\title{
ANALES DE LA UNIVERSIDAD DE CHILE, SEXTA SERIE, Nº 16, DICIEMBRE DE 2004
}

El tema que abordan diferentes autores en esta publicación periódica de la Universidad de Chile en su espacio "Estudios" es la educación. En "Comunicaciones" se refieren a temas de desarrollo y recursos humanos. A su vez, el documento incluye la Cuenta Anual del rector de esta casa de estudios y algunas reseñas.

El primer estudio es del ex rector Luis Riveros. Propone éste la necesidad de que los currículos, tanto de la educación secundaria como superior, deben ser más flexibles. Ello porque hoy los estudiantes acceden a tantas fuentes de conocimiento y el mundo cambia tan rápidamente respecto de los conocimientos y competencias necesarias para desempeñarse, que la rigidez curricular puede afectar la buena formación. Sugiere, enumerando las características necesarias, que el profesor actual debería enfrentar a sus alumnos con una mentalidad de flexibilidad curricular y de gestión más que de traductor de contenidos. Lo mismo debería ocurrir en la educación superior, orientado esta vez hacia las competencias de los estudiantes en sus respectivas especialidades. Durante estos últimos años se han buscado caminos para mejorar la formación docente y lo que plantea el profesor Riveros debería estar incluido, sin duda, en la formación de profesores del país.

En otro plano de la reflexión educacional, Fernando Lolas analiza los dilemas por los que atraviesa actualmente el quehacer universitario y los valores fundamentales permanentes de la educación terciaria. Nos recuerda debates que, por más de dos décadas, circulan por nuestro entorno; por ejemplo, lo referido al lucro en la educación superior, la globalización y la función del Estado, y quiénes entre los protagonistas de tejido social deben hacerse cargo de la investigación. 
El profesor Patricio Meller expone los desafíos de la universidad para el siglo XXI, concluyendo que es ineludible que ésta cambie su propuesta social vigente desde hace 200 años. El problema, más bien, es dilucidar cómo va a producirse ese cambio. El profesor Rosselot presenta la situación actual y las perspectivas en la enseñanza de las ciencias de la salud, y respalda fundadamente los procesos de acreditación en estas especialidades. Las profesoras Zemelman y Jara entregan una perspectiva histórica del sistema educacional en Chile desde los años 60, haciendo especial énfasis en las desigualdades sociales y en cómo éstas se vinculan con los sistemas educacionales del último siglo en el país. Las docentes Romeo y Llaña plantean la necesidad de fortalecer una visión socializada en la enseñanza de los valores de la democracia, por su implicancia para la humanización del proyecto país.

Este tomo de los Anales es, sin duda, un aporte al debate sobre la enseñanza en Chile. Como consecuencia de las diversas visiones y perspectivas acerca de este tópico, algunos consensos parecen difíciles de lograr, pero debemos aceptar esto como una rica fuente de discusión. Lo que nunca deberíamos olvidar, independientemente de nuestras particulares miradas, es el apego a los datos duros y la rigurosidad en el análisis al exponer nuestros argumentos.

Paulina Dittborn Vicerrectora académica Universidad Tecnológica de Chile INACAP Corporación pdittborn@inacap.cl 